Revue d'histoire de l'Amérique française

DEVUE D.HISTOIRE DE L'AMÉRIQUE FRANÇAISE

\title{
Des dames chrétiennes. La spiritualité des catholiques québécoises au $\mathrm{XIX}^{\mathrm{e}}$ siècle
}

\section{Christine Hudon}

Volume 49, numéro 2, automne 1995

URI : https://id.erudit.org/iderudit/305415ar

DOI : https://doi.org/10.7202/305415ar

Aller au sommaire du numéro

Éditeur(s)

Institut d'histoire de l'Amérique française

ISSN

0035-2357 (imprimé)

1492-1383 (numérique)

Découvrir la revue

Citer cet article

Hudon, C. (1995). Des dames chrétiennes. La spiritualité des catholiques québécoises au XIX ${ }^{\mathrm{e}}$ siècle. Revue d'histoire de l'Amérique française, 49(2), 169-194. https://doi.org/10.7202/305415ar
Résumé de l'article

Cet article sur la spiritualité féminine au XIX ${ }^{\mathrm{e}}$ siècle examine successivement les sources d'origine cléricale et les écrits intimes laissés par les femmes. Les premières révèlent une " féminisation » de la piété, se manifestant notamment par le renouvellement de la dévotion mariale et par le culte de la

Sainte-Famille, ainsi qu'une insistance grandissante sur les devoirs des filles, des mères et des épouses. Les seconds, composés de lettres et de six journaux personnels, dénotent une grande adhésion de leurs auteures aux enseignements de l'Église. Dans leurs réflexions sur les retraites spirituelles, sur les prières, sur la confession et sur la communion, ces femmes font écho aux propos des prêtres. Leurs doutes et leurs remises en question s'accompagnent de remords et de culpabilité.
Tous droits réservés @ Institut d'histoire de l'Amérique française, 1995
Ce document est protégé par la loi sur le droit d'auteur. L'utilisation des services d'Érudit (y compris la reproduction) est assujettie à sa politique d'utilisation que vous pouvez consulter en ligne.

https://apropos.erudit.org/fr/usagers/politique-dutilisation/ 


\section{DES DAMES CHRÉTIENNES LA SPIRITUALITÉ DES CATHOLIQUES QUÉBÉCOISES AU XIX ${ }^{\mathrm{e}}$ SIÈCLE ${ }^{1}$}

CHRISTINE HUDON

Université de Yale

\section{RÉSUMÉ}

Cet article sur la spiritualité féminine au XIX ${ }^{\mathrm{e}}$ siècle examine successivement les sources d'origine cléricale et les écrits intimes laissés par les femmes. Les premières révèlent une «féminisation» de la piété, se manifestant notamment par le renouvellement de la dévotion mariale et par le culte de la Sainte-Famille, ainsi qu'une insistance grandissante sur les devoirs des filles, des mères et des épouses. Les seconds, composés de lettres et de six journaux personnels, dénotent une grande adhésion de leurs auteures aux enseignements de l'Église. Dans leurs réflexions sur les retraites spirituelles, sur les prières, sur la confession et sur la communion, ces femmes font écho aux propos des prêtres. Leurs doutes et leurs remises en question s'accompagnent de remords et de culpabilité.

\section{ABSTRACT}

This study of nineteenth-century female spirituality draws on church documents and women's personal writings. The first type of source reveals a feminization of piety expressed notably in the renewal of Marial devotions and in the cult of the Holy Family, and a growing emphasis on the duties of daughters, mothers, and wives. Composed of letters and six diaries, the personal papers show the strong adhesion of their authoresses to the teachings of the Church. In their thoughts on spiritual retreats, prayers, confession, and communion, these women echo priests' formulations. Feelings of remorse and guilt accompany their doubts and their soulsearching.

Jusqu'ici, la spiritualité féminine a peu retenu l'attention des historiens québécois. S'il est par exemple question de religion dans l'ouvrage du Collectif Clio, c'est pour évoquer brièvement l'importance du sentiment religieux dans la société préindustrielle, les interdits en matière de sexualité et de contraception et l'alternative à

1. Cet article a pu être réalisé grâce à une bourse du Conseil de recherches en sciences humaines du Canada (CRSH). Je remercie Denyse Baillargeon, Serge Gagnon, André Poulin et Jean Roy pour leurs critiques et leurs suggestions. 
la maternité qu'offre le célibat consacré . Dans le tableau qui nous est brossé, les femmes travaillent, étudient, accouchent et élèvent des enfants, se divertissent, écrivent, revendiquent et militent, mais ne prient jamais. L'histoire religieuse de type scientifique a également tardé à explorer la spiritualité. Ces trente dernières années, les recherches ont largement porté sur les structures institutionnelles, sur la pensée politico-religieuse des clercs et sur le travail accompli par les communautés religieuses. Ces aspects sont certes indispensables à une meilleure compréhension de l'influence de la religion, mais celle-ci doit aussi être envisagée comme un système de croyances imprégnant profondément les comportements et les mentalités.

Parmi les livres et les articles qui traitent de la religion des femmes, beaucoup visent moins à analyser les discours et les pratiques qu'à présenter des modèles de vertu et de piété ou de militantisme et d'engagement social ${ }^{3}$. Dans ce dernier cas, ils ne font qu'effleurer la vie spirituelle des protagonistes. Cet intérêt pour le moins mitigé ressort encore plus clairement quand on découpe le champ historique en aires chronologiques. De grands vides apparaissent alors. En regard de l'époque pionnière, celle où ont œuvré les Marguerite Bourgeois, Marie de l'Incarnation, Kateri Tekakwitha et Marguerite d'Youville, et de l'époque des catholiques militantes du $\mathrm{XX}^{\mathrm{e}}$ siècle, il semble qu'on ait jugé le $\mathrm{XIX}^{\mathrm{e}}$ siècle digne de bien peu d'intérêt. Dans les travaux qui couvrent cette dernière période, la spiritualité féminine est tantôt monolithique, tantôt pathologique comme chez la Julie Bruneau-Papineau de Fernand Ouellet, mélancolique, pessimiste et «imbue du plus noir jansénisme ${ }^{4} »$.

Des recherches récentes se démarquent cependant. Elles soulignent les évolutions touchant la spiritualité et cherchent à les lier aux transformations que connaissent l'Église et la société. L'étude fouillée que Marie-Aimée Cliche a consacrée aux pratiques de dévotion montre la place croissante des femmes dans les confréries ${ }^{5}$, phé-

2. Collectif Clio, L'histoire des femmes au Québec depuis quatre siècles (Montréal, Le Jour, 1992), 127, 185, 235-239, 301-302.

3. Citons deux livres très différents qui se rattachent d'une façon ou d'une autre à ce genre toujours florissant: Giselle Huot, Une femme au séminaire. Marie de la Charité (18521920) fondatrice de la première communauté dominicaine du Canada (1887) (Montréal, Bellarmin, 1987), 525 p.; Hélène Pelletier-Baillargeon, Marie Gérin-Lajoie. De mère en fille, la cause des femmes (Montréal, Boréal Express, 1985), 382 p.

4. F. Ouellet, «Le destin de Julie Bruneau-Papineau (1796-1862)», Bulletin des recherches historiques, 64,1-2 (1958): 7-31, 35-63. L'article se présente comme un essai de caractérologie et vise à saisir l'influence de Julie sur son mari et sur ses enfants. Voir aussi «Le destin tragique de la mère de Henri Bourassa», Annales de l'ACFAS, 27 (1961): 83-84, d'où est tirée la citation.

5. M.-A. Cliche, Les pratiques de dévotion en Nouvelle-France. Comportements populaires et encadrement ecclésial dans le gouvernement de Québec (Québec, Presses de l’Université Laval, 1988), 182. 
nomène également souligné par Brigitte Caulier qui y décèle des motifs d'ordre social tout autant que religieux ${ }^{6}$. Lieux de sociabilité et d'entraide mutuelle, les associations pieuses fournissaient à leurs membres un rempart contre la solitude, susceptible d'apaiser la peur de mourir seule. En outre, elles contribuaient efficacement à diffuser les pratiques et les objets alimentant une piété en constant renouvellement. Au sujet, justement, des mutations de la piété, Marta Danylewycz a succinctement évoqué, dans son livre posthume sur les vocations religieuses, la «révolution cultuelle» du milieu du XIX ${ }^{\mathrm{e}}$ siècle en insistant sur l'essor de la dévotion mariale qui exalte le dévouement, la soumission et la pureté 7 . Elle suggère que cette dévotion eut des effets complexes et variés sur les comportements. Pour certaines femmes, la religion représentait un refuge et n'incitait guère à la remise en question de l'ordre établi. Pour d'autres, au contraire, elle agissait comme un puissant stimulant invitant au dépassement personnel, à l'action sociale et à la revendication féministe.

Dans la foulée de ces travaux, le présent article propose d'examiner la spiritualité féminine à la lumière de deux types de sources: les écrits d'origine cléricale et les témoignages intimes laissés par les femmes. Grâce aux premières, constituées essentiellement de mandements, de lettres pastorales, de sermons, de rapports pastoraux et de livres édifiants, j'évoquerai les jugements portés par les prêtres sur la piété féminine, puis je présenterai les traits saillants de la spiritualité proposée aux laïques catholiques du $\mathrm{XIX}^{\mathrm{e}}$ siècle. Dans un deuxième temps, six journaux personnels, des lettres de la Collection Baby couvrant la fin du XVIII ${ }^{e}$ et le $\mathrm{XIX}^{\mathrm{e}}$ siècles, ainsi que la correspondance de Julie Bruneau-Papineau témoigneront de la façon dont ces femmes ont accueilli, compris et reformulé le message de l'Église. Quatre aspects importants de la vie religieuse seront scrutés: les retraites spirituelles qui donnèrent lieu à maintes réflexions et résolutions, les prières et, enfin, la confession et la communion, deux rites placés au cœur de la pratique sacramentelle. Nous verrons que, dans une large mesure, ces témoignages font écho aux écrits cléricaux. J'aurais souhaité disposer d'une documentation donnant la parole autant aux paysannes et aux ouvrières qu'aux bourgeoises, et autant aux rurales qu'aux citadines, mais tel n'est malheureusement pas le cas. $\mathrm{Au} \mathrm{XIX}^{\mathrm{e}}$ siècle, l'activité épistolaire et, plus encore, l'écriture

6. B. Caulier, Les confréries de dévotion à Montréal, 17e-19e siècles, thèse de doctorat (histoire), Université de Montréal, 1986, 51-61.

7. M. Danylewycz, Profession: religieuse. Un choix pour les Québécoises (1840-1920) (Montréal, Boréal, 1988), 39-55. 
d'un journal intime sont avant tout pratiquées par l'élite ${ }^{8}$. Mon corpus est tributaire de cette réalité; un journal concerne une jeune institutrice d'une paroisse rurale, les cinq autres ont pour auteures des femmes de milieux aisés.

\section{PROPOS DE CLERCS}

Plusieurs clercs ont livré leur appréciation de la pratique religieuse des fidèles en prenant soin de distinguer hommes et femmes. La correspondance et les rapports pastoraux dressés après 1840 contiennent en effet des statistiques ou, beaucoup plus fréquemment, des allusions et des sous-entendus qui témoignent d'un certain dimorphisme sexuel dans les comportements religieux et dans les attitudes morales. En 1864 , le curé de Notre-Dame-du-Rosaire, du diocèse de SaintHyacinthe, note ainsi qu'en général, «les mères et les filles chrétiennes sont bonnes, pieuses et exactes à s'approcher des sacrements de pénitence et d'eucharistie». Les hommes ne méritent pas les mêmes éloges: bon nombre d'entre eux sont réputés «insouciants pour les devoirs religieux ${ }^{9} »$. Quelques années plus tôt, un autre prêtre accuse de négligence l'élément masculin de sa paroisse ${ }^{10}$. Plusieurs de ses confrères posent un jugement semblable. Ils déclarent que la différence essentielle entre les deux sexes réside surtout dans l'accomplissement des pratiques surérogatoires. Hommes et femmes sont fidèles, disent-ils, à remplir leur devoir pascal, mais celles-ci se confessent et communient plus souvent le reste de l'année ${ }^{11}$. Les écrits de quelques femmes reflètent, de façon plus ou moins directe, ces constatations. Afin de convaincre l'évêque qu'un curé doit s'installer

8. Sur la littérature intime au Québec, lire entre autres l'introduction de Jean-Louis Major dans Henriette Dessaulles, Journal (Montréal, Presses de l'Université de Montréal, 1989); Yvan Lamonde, Je me souviens. La littérature personnelle au Québec (1860-1980) (Québec, Institut québécois de recherche sur la culture (IQRC), 1983), 275 p.; Manon Brunet et Serge Gagnon, dir., Discours et pratiques de l'intime (Québec, IQRC, 1993), 267 p.; Denise Lemieux et Lucie Mercier, Les femmes au tournant du siècle, 1880-1940. Âges de la vie, maternité et quotidien (Québec, IQRC, 1991), 398 p.

9. Archives de l'évêché de Saint-Hyacinthe (dorénavant AESH), XVIII, 62 (NotreDame-du-Rosaire), Rapport sur la paroisse, 1864. À la différence des enquêtes pastorales françaises, les questionnaires québécois interrogent peu les curés sur d'éventuelles différences entre hommes et femmes.

10. AESH, IV. D.4, Tableau de la paroisse de Saint-Mathieu-de-Beloeil, 1841.

11. Selon la correspondance et les rapports pastoraux des diocèses de Saint-Hyacinthe et de Montréal. Nive Voisine fait le même constat pour le diocèse de Rimouski. Voir N. Bélanger et N. Voisine, dir., Le diocèse de Rimouski (1867-1992) (Rimouski, Archevêché de Rimouski, 1994), 65. Plus tard, au $X X X^{\mathrm{e}}$ siècle, les oblats d'une paroisse montréalaise critiqueront ces «hommes qui refusent d'aller se confesser». Lucia Ferretti, Entre voisins. La société paroissiale en milieu urbain: Saint-Pierre-Apôtre de Montréal, 1848-1930 (Montréal, Boréal, 1992), 239, note 6. 
dans sa paroisse, l'une d'elles soutient que plusieurs femmes ne peuvent communier aussi souvent qu'elles le souhaitent en raison de la distance les séparant de leur confesseur ${ }^{12}$. Une autre, résidante de Stanbridge, affirme qu'il fut «édifiant de voir autant d'hommes communier» lors d'une messe dédiée à la Vierge $\mathrm{Marie}^{13}$. Sa remarque confère implicitement une signification particulière à la pratique eucharistique des hommes. Sans doute s'explique-t-elle en partie par l'expérience personnelle du témoin, car, selon son journal, son mari et son fils s'approchaient beaucoup moins souvent des sacrements que les femmes de la maison. En 1865, la diariste communia par exemple tous les mois, sa fille reçut l'eucharistie cinq fois, alors que son fils de 31 ans se contenta de satisfaire à son devoir pascal.

Ces comportements asymétriques sont avant tout le produit d'une éducation, le résultat des normes et des exigences sociales et religieuses imposées aux femmes. Au siècle dernier, les élites laïques cherchèrent de plus en plus à confiner les femmes à la maison et à en faire de «bonnes épouses» et de «bonnes mères», aimantes et dévouées ${ }^{14}$. Le discours de l'Église prenait une coloration semblable. $\mathrm{Au} \mathrm{XIX}{ }^{\mathrm{e}}$ siècle, et surtout après 1840 , les prédicateurs firent rimer féminité avec piété. Dans le contexte du catholicisme québécois, et même occidental, cette insistance croissante fut notamment favorisée par l'essor de la piété ultramontaine, appuyée sur une imagerie exaltant le quotidien féminin et l'univers familial. Voyons un peu plus en détail quels furent les principaux traits de l'enseignement clérical.

\section{Les attributs féminins de l'Église et de la piété catholiques}

Les appellations et les allégories servant à désigner la religion et l'Église ont été multiples et changeantes au fil des siècles. Parmi ces

12. AESH, XVII, c.35 (Saint-Hilaire), Henriette Campbell à $\mathrm{M}^{\mathrm{gr}}$ Bourget, 17 juillet 1848.

13. Université McGill, Rare Books Department (dorénavant McGill), madame Henri DesRivières (Angélique Hay), Personal diary, 23 juillet 1849. Les dix cahiers manuscrits, les uns en français, les autres en anglais, ont été consultés. Ils couvrent, de façon discontinue, la période 1843-1872. Madame DesRivières était l'épouse d'un riche propriétaire foncier de Stanbridge dans les Cantons de l'Est. Elle prenait une part active à la vie religieuse de sa paroisse où elle touchait l'orgue, chantait, s'occupait de décorer l'église et de parer les autels. Sa maison était un lieu de rassemblement pour les prêtres du voisinage.

14. Une abondante littérature a été consacrée à ce sujet. Sur le Québec, lire Allan Greer, «La république des hommes: les Patriotes de 1837 face aux femmes», RHAF, 44,4 (printemps 1991): 507-528; Nathalie Picard, Les femmes et le vote au Bas-Canada de 1792 à 1849, mémoire de maitrise (histoire), Université de Montréal, 1992, en particulier les pages 33-68. Exemple parmi d'autres de ce discours, une conférence du juge Mondelet donnée en 1847 à l'Institut Canadien et intitulée «La position de la femme canadienne» privilégie «l'éducation du cœur» et l'apprentissage des travaux ménagers. Voir Yvan Lamonde, Gens de parole. Conférences publiques, essais et débats à l'Institut Canadien de Montréal (1845-1871) (Montréal, Boréal, 1990), 70. 
représentations, les références plus ou moins directes aux figures féminines ont joui d'une certaine pérennité, en s'affirmant toutefois avec plus ou moins de vigueur et d'insistance selon les époques. Dans son étude sur la prédication sulpicienne des années 1800-1830, Louis Rousseau note ainsi la tendance des prêtres à dépeindre d'abord l'Église comme «la société des fidèles qui sous la conduite des pasteurs légitimes ne font qu'un même corps dont Jésus-Christ est le chef $^{15}{ }$ ». On utilise alors rarement pour la décrire des attributs féminins, comme l'épouse de Dieu ou la mère des chrétiens ${ }^{16}$. Les mandements et les lettres pastorales des évêques témoignent du même phénomène. Dans les documents officiels émanant de l'évêché de Québec entre 1806 et 1850 , on ne trouve que deux références à l'Église-mère, mais elles se multiplient pendant la période 1850$1871^{17}$. Elles sont particulièrement nombreuses dans les écrits consacrés à la question de l'unité italienne et des États pontificaux, où c'est «notre Sainte Mère l'Église» qui apparaît comme la victime des «persécutions». À lui seul, le «mandement pour établir l'œuvre du denier de Saint-Pierre» en date du 19 mars 1862 évoque cette image à trois reprises. Dans la seconde moitié du XIX ${ }^{\mathrm{e}}$ siècle, le clergé établit en somme un rapprochement entre l'expérience féminine et les difficultés de l'Église. «L'Église souffrante» est définitivement femme, mère et épouse.

La piété tend également à se féminiser. L'essor du culte marial en est la manifestation la plus éclatante. Bien sûr, la dévotion à la Vierge n'est pas propre au catholicisme du $\mathrm{XIX}^{\mathrm{e}}$ siècle, mais elle bénéficie d'une vigoureuse impulsion avec la proclamation du dogme de l'Immaculée Conception, en 1854. L'influence de la piété romaine et la popularité croissante des idées de saint Alphonse-Marie de Liguori, qui infléchissent progressivement la pastorale après 1840, concourent aussi à ce renouvellement ${ }^{18}$. Une phrase de $\mathrm{M}^{\mathrm{gr}}$ Bourget confirme les nouvelles conceptions qui orientent l'activité cléricale et illustre le ton du message religieux adressé aux catholiques. Commentant un décret du premier concile provincial de Québec, l'évêque de Montréal invite les prêtres à faire «aimer cette tendre Mère dont les mamelles sacrées

15. Louis Rousseau, La prédication à Montréal de 1800 à 1830: approche religiologique (Montréal, Fides, 1976), 181.

16. Ibid., 182.

17. $M E ́ Q$, tome 3: (1806-1850) et tome 4: (1850-1871).

18. Voir C. Hudon, Encadrement clérical et vie religieuse dans le diocèse de SaintHyacinthe, 1820-1875, thèse de doctorat (études québécoises), Université du Québec à TroisRivières, 1994. Sur le renouvellement des dévotions, consulter aussi B. Caulier, op. cit., 243301; Philippe Sylvain et Nive Voisine, Nive Voisine, dir., Histoire du catholicisme québécois, II: Les XVIIle et XIXe siècles, 2: Réveil et consolidation (1840-1898) (Montréal, Boréal, 1991), 347-351. 
allaitent les brebis et les agneaux ${ }^{19}{ }$. Une pléthore d'œuvres et d'associations, de pratiques et d'exercices sont mis au service de cet objectif. Dans la décennie 1830, la confrérie de Notre-Dame-Auxiliatrice connaît une belle croissance, puis tend à s'éclipser au profit de nouvelles associations, comme l'Archiconfrérie du Très Saint et Immaculé Cœur de Marie qui se diffuse rapidement grâce aux retraites et aux missions paroissiales des années 1840 . Vers la même époque, la congrégation des Enfants de Marie recrute une large partie de ses membres chez les couventines. Les sociétés de tempérance et diverses organisations de charité sont aussi placées sous le patronage de la Vierge. La peinture et la statuaire la représentent sous différents attributs, tandis que la toponymie puise abondamment dans le large répertoire des vocables marials ${ }^{20}$. Durant toute l'année liturgique, des fêtes commémorent les grands événements de la vie de Marie et célèbrent l'un ou l'autre des aspects de son culte. À compter de 1838, un nombre croissant de paroisses lui consacrent le mois de mai. Alors que la température s'adoucit et que la nature reprend vie, la prédication célèbre l'innocence, la pureté et les chastes bonheurs de la vie éternelle en une série d'exercices susceptibles de faire contrepoids à l'exubérance et aux divertissements profanes de la belle saison ${ }^{21}$. Prières, sermons, cantiques, livres de dévotion, images pieuses, scapulaires et médailles exaltent les vertus de la Madone, lui confèrent force et puissance et soulignent sa participation à la Rédemption.

Dans les décennies 1860 et 1870 , les dévotions à sainte Anne, à saint Joseph et au Sacré-Cœur-de-Jésus gagnent elles aussi en popularité et se voient à leur tour consacrer un mois de l'année. Même si Saint-Joseph et le Sacré-Cœur de Jésus sont des figures masculines, ils revêtent des qualités attribuées d'abord aux femmes: l'humilité et le dévouement, le sacrifice et la sensibilité. Cette piété sentimentale fait une grande place à la famille et magnifie le bonheur domestique. À travers les chemins de la Croix, elle évoque longuement la douleur et les souffrances en traçant un parallèle entre la vie humaine et la

19. Lettre pastorale, $1^{\text {er }}$ janvier 1853 , dans Mandements, lettres pastorales, circulaires et autres documents publiés dans le diocèse de Montréal depuis son érection (dorénavant MÉM), 2: 334 .

20. Voir Pierre Savard, Aspects du catholicisme canadien-français au XIXe siècle (Montréal, Fides, 1980), 163. Au sujet de la peinture, lire Jean Simard, Les arts sacrés au Québec (Boucherville, Éditions de Mortagne, 1989), 143-145, qui donne l'exemple de la chapelle de Notre-Dame-de-Lourdes à Montréal.

21. C'est $\mathrm{M}^{\mathrm{gr}}$ Bourget qui lance cette pratique dans le diocèse de Montréal. Voir B. Caulier, op. cit., 257. Sur le choix du mois de mai pour célébrer Marie, voir Michela De Giorgio, «La bonne catholique», G. Duby et M. Perrot, dir., Histoire des femmes en Occident, 4: G. Fraisse et M. Perrot, Le XIXe siècle (Paris, Plon, 1991), 174-175. 
Passion du Christ. Les manifestations religieuses sont empreintes de faste et de symboles où abondent les fleurs, les couronnes, les larmes, les épines, les croix et les cœurs ensanglantés. Deux thèmes, l'amour de Dieu et la protection des saints, reviennent fréquemment dans la prédication et contribuent à faire reculer l'image, toujours présente mais désormais moins menaçante, du Dieu vengeur.

Autre signe d'une piété qui se féminise: plusieurs biographies publiées au XIX ${ }^{\mathrm{e}}$ siècle sont consacrées aux héroïnes de la NouvelleFrance. Marguerite d'Youville, Marguerite Bourgeois, Jeanne Mance et Jeanne Le Ber inspirent le sulpicien Étienne-Michel Faillon ${ }^{22}$. L'abbé Henri-Raymond Casgrain chante quant à lui les mérites de Marie de l'Incarnation ${ }^{23}$. Ici encore, les modèles chrétiens sont des femmes, religieuses ou laïques.

Cette piété, qui s'adresse à tous les catholiques, imprègne particulièrement l'enseignement dispensé aux jeunes filles et aux mères. De plus en plus nombreuses dans la seconde moitié du siècle, les retraites spécialisées contribuent largement à former les consciences chrétiennes en inculquant à chacune les vertus de son «état». Comme ils rassemblent les fidèles d'un même sexe, d'un même groupe d'âge et, parfois, de même condition sociale ${ }^{24}$, ces événements permettent en effet au clergé d'adapter son discours aux différents publics. Chasteté, modestie, réserve, dévouement et résignation constituent les maîtres mots de cet enseignement où les femmes se voient attribuer une mission salvatrice.

\section{La vertu rédemptrice}

En septembre $1700, \mathrm{M}^{\mathrm{gr}}$ de Saint-Vallier, deuxième évêque de Québec, confiait aux parents la tâche d'enseigner à leurs enfants les prières et les principes de la religion ${ }^{25}$. Ses successeurs formulèrent les

22. E.-M. Faillon, Vie de Mme d'Youville, fondatrice des Soeurs de la Charité de Villemarie dans l'Ile de Montréal, en Canada (Villemarie, Sœurs de la Charité, Hôpital général, 1852), xxix-491 p.; Vie de la Soeur Bourgeois, fondatrice de la Congrégation de Notre-Dame de Villemarie en Canada (Paris, Poussielgue-Rusand, 1852-1853), 2 vol.; Vie de Mademoiselle Mance et histoire de l'Hôtel-Dieu de Villemarie en Canada (Paris, Poussielgue-Rusand, 1854), 2 vol.; L'hérö̈ne chrétienne du Canada, ou, Vie de Mlle Le Ber (Villemarie, Sœurs de la Congrégation de Notre-Dame, 1860), 404 p.

23. H.-R. Casgrain, Histoire de la Mère Marie de l'Incarnation, première supérieure des Ursulines de la Nouvelle-France, précédée d'une esquisse sur l'histoire religieuse des premiers temps de cette colonie (Québec, G. E. Desbarats, 1864), 467 p.

24. À Montréal, il existe des retraites pour les servantes à la fin du XIX $\mathrm{X}^{\mathrm{e}}$ siècle. Ces temps forts de la vie religieuse ne sont pas réservés à l'élite, mais visent, au contraire, à toucher un large public.

25. Mandement, $1^{\text {er }}$ septembre $1700, M E ́ Q, 1: 386-388$. 
mêmes exhortations, que les curés reprirent à leur tour dans leurs prônes et leurs sermons dominicaux. Un mandement des évêques de la province ecclésiastique de Québec, rédigé en 1853, invitait ainsi les pères et mères à repasser de temps à autre avec leur progéniture «les différents chapitres du catéchisme» et les chargeait d'apprendre à leurs enfants «à aimer Dieu» en citant, au passage, cette parole de saint Augustin: «Ô mon Dieu, l'amour de votre Saint Nom, je l'ai sucé avec le lait de ma mère! ${ }^{26}$ »

En plus d'apparaître sur les documents épiscopaux, ce discours sur les devoirs des parents, et tout particulièrement sur la responsabilité des mères, bénéficia, au $\mathrm{XIX}^{\mathrm{e}}$ siècle, de puissants relais de transmission avec la multiplication des moyens d'encadrement et de formation comme les retraites spécialisées, les associations pieuses et les établissements scolaires catholiques ${ }^{27}$. De façon récurrente, le clergé s'adressa aux femmes et les incita à accomplir avec zèle leur tâche d'éducatrice. L'essor du culte marial et la diffusion d'une piété sentimentale contribuèrent à renforcer l'insistance sur ce rôle et à lui donner une étendue considérable, dépassant la simple transmission des principes élémentaires de la foi chrétienne. Dans les sermons, les périodiques et les livres pieux, la femme apparait comme un ange au foye ${ }^{28}$. Par sa piété, sa modestie et son dévouement, elle forme les consciences, édifie son époux et ses enfants. Elle leur permet de gagner leur salut ou, au contraire, leur ouvre les portes de l'enfer. L'abbé Alexis Mailloux, grand vicaire de l'évêque de Québec, insiste longuement sur ce thème dans son Manuel des parents chrétiens. «Les femmes sauvent ou perdent le monde suivant qu'elles sont bonnes ou mauvaises», affirme-t-il, ajoutant qu'on pourrait «dire, sans crainte de se tromper, que, pendant tout le cours de leur vie, les hommes sont presque toujours tels qu'ils sont sortis des mains de leurs mère ${ }^{29}{ }^{2}$. La prédication servie aux Montréalaises au $\mathrm{XIX}^{\mathrm{e}}$ siècle développe la même idée. Brigitte Caulier a noté qu'après 1830, les directeurs de la confrérie des dames de la Sainte-Famille rappellent régulièrement aux consœurs l'importance de rester modestes dans leur tenue. En ce «siècle de luxure», l'exemple des mères sur leurs filles est jugé très

26. Mandement, 8 septembre $1853, M E ́ Q, 4: 98-109$.

27. L'importance des couvents en cette matière est soulignée dans Micheline Dumont et Nadia Fahmy-Eid, dir., Les couventines. L'éducation des filles au Québec dans les congrégations religieuses enseignantes 1840-1960 (Montréal, Boréal, 1986), 315 p.

28. Cette expression est également utilisée par les penseurs laïcs. Voir Katherine Blundel, Le travail et la vertu. Femmes au foyer: une mystification de la Révolution industrielle (Paris, Payot, 1982), 43.

29. A. Mailloux, Manuel des parents chrétiens ou Devoirs des pères et des mères dans l'éducation religieuse de leurs enfants (Montréal, VLB, 1977), première édition 1851), 63. 
important. Le sulpicien Martineau, directeur de la confrérie à partir de 1866 , insiste plus que ses prédécesseurs sur les devoirs maternels ${ }^{30}$. D'autres exemples sont fournis par Marie-Louise Globensky-Lacoste qui s'applique à résumer, dans son journal, les instructions pastorales auxquelles elle a assisté. Elle écrit au cours du carême de l'année 1897:

Dans l'après-midi je suis allée avec Jeanne à Notre-Dame entendre la conférence de l'Abbé de Montigny spécialement pour les femmes. Ce savant prédicateur a été magnifique. Son sujet était: la femme forte, son influence dans la famille et dans la société. Il nous a parlé longuement de Clotilde comme un modèle de piété chrétienne. Avant tout elle voulait rester fidèle à son Dieu et par son dévouement elle obtint la conversion de son époux infidèle et sauva la France. Voilà ce que peuvent la prière et le sacrifice. Chaque femme chez elle doit être apôtre et sauver les âmes par sa prière constante ${ }^{31}$.

Cet enseignement établit diverses comparaisons entre la vocation sacerdotale et la «mission» de la mère, que l'on dit «grande et sublime». La femme est comme un prêtre au foyer, explique un prédicateur jésuite aux dames de la Charité réunies en retraite. $\mathrm{Au}$ sortir d'un sermon, madame Globensky-Lacoste note: «Le prédicateur s'est surpassé. Il a montré comment la vraie mère était vraiment le support de l'Église en lui préparant des saints. Dans sa maison [...] qui est son temple elle peut faire l'œuvre du Ministre du Seigneur ${ }^{32} . » \mathrm{De}$ façon semblable, le destin de la Vierge est présenté en exemple. Avec pour modèle la «Mère des douleurs» devant la croix, «la femme chrétienne sauvera le monde ${ }^{33} \gg$. À travers ces instructions, la femme est en somme investie d'une mission rédemptrice auprès de ses enfants et de son mari, parfois représenté sous les traits d'un homme tiède ou même indifférent, finalement converti par la vertu de sa conjointe.

Tout comme les épouses et les mères, les jeunes filles assument d'importantes responsabilités. Leur comportement a valeur d'exemple

30. B. Caulier, op. cit., $361,366$.

31. Notons que ce discours sur la capacité de la femme à transformer la société, par sa vertu, colore fortement les écrits des féministes «maternelles». Archives nationales du Québec à Montréal (dorénavant ANQM), P76/6, Journal de Lady Lacoste (Marie-Louise Globensky), 12 mars 1897. Née en février 1849 de Léon Globensky et d'Angélique Limoges, Marie-Louise épousa l'avocat Alexandre Lacoste le 6 mai 1866. Elle donna naissance à douze enfants dont Justine, fondatrice de l'hôpital Sainte-Justine et Marie, féministe et mère de Marie Gérin-Lajoie. Les quinze cahiers manuscrits, qui s'échelonnent de 1864 à 1916, ont été consultés. Cinq d'entre eux ont été rédigés avant son mariage.

32. lbid., 25 octobre 1893.

33. Ibid., 9 avril 1897. 
et peut suffire à toucher l'âme de ceux qui les entourent, que ce soient les parents, les frères et sœurs ou les «étrangers». C'est la thèse que défend un livre publié au cours des années 1870 pour l'édification des adolescentes. L'héroïne, Ernestine Rodier, est une jeune fille exemplaire, décédée prématurément de la tuberculose. Témoin de son comportement vertueux, sa compagne de chambre, une jeune protestante, abjure sa foi et se convertit au catholicisme ${ }^{34}$. Dans un registre semblable, un livre paru à la même époque raconte la vie vertueuse de Marie-Lucie-Hermine Frémont, première carmélite canadienne ${ }^{35}$. L'ouvrage exalte l'esprit d'abnégation, la gravité, la pureté et l'innocence de cette enfant qui récite de courtes invocations en s'habillant, réitérant à chaque vêtement qu'elle endosse son désir de se conserver chaste. Ainsi, en enfilant sa robe, elle prie: «Ô Jésus, mon aimable époux! revêtez-moi de la virginité comme d'une robe nuptiale, afin que je mérite d'être introduite dans la salle du festin, où se célèbrent éternellement les noces de l'Agneau». Au moment de passer sa ceinture, elle récite: «Ceignez-moi, Jésus, de la pureté comme d'une ceinture et éteignez en moi toute concupiscence, afin que je conserve toujours la chasteté et la virginité ${ }^{36}$.» Sainte Cécile, sainte Lucie et sainte Agnès sont ses modèles. Avec Philomène, ces vierges et martyres se retrouvent alors dans plusieurs sermons ${ }^{37}$.

Sans nécessairement recourir aux images et au style doucereux des récits hagiographiques, l'entourage immédiat des jeunes filles reprend les mêmes exhortations, les incitant à la vertu et à la fréquentation assidue des sacrements. À quelques reprises, l'abbé Joseph de Gonzague prodigue à ses deux nièces, Anna et Clémentine, des conseils sur la façon d'être «de bonnes filles». «Soyez toujours les modèles de vos petits frères et sœurs par votre obéissance, soumission, piété, par vos vertus enfin», recommande-t-il en novembre 1892. Étant «les plus vieilles de la famille, vous êtes le point de mire et vos petits frères et sœurs sont portés à faire ce que vous faites et à vous imiter en toutes choses $^{38}$ ».

34. The Violet of our Villa. A Sketch of the Life and Virtues of Miss Ernestine Rodier, a Pupil of the Graduating Course of Villa Maria (Montreal, 1875), 81 p.

35. R. P. Braün, Une fleur du Carmel. La première carmélite canadienne, Marie-LucieHermine Frémont, en religion sæur Thérèse de Jésus (Québec, Léger et Brousseau, 1875), 464 p. Son présentateur assure que ce livre contient des extraits authentiques du journal intime de la jeune fille.

36. Ibid., 55 .

37. Voir l'article que Pierre Savard a consacré à sainte Philomène, "patronne de l'innocence des jeunes filles» dans Aspects du catholicisme..., op. cit., 173-196.

38. Ces deux lettres sont recopiées dans le Journal d'Anna de Gonzague, Archives de l'Université Laval (dorénavant AUL), P 224. Anna est née le 18 octobre 1873. Elle commença son journal en septembre 1892, alors qu'elle était institutrice à Saint-Michel-des-Saints. La dernière inscription date du 25 novembre 1898. 
À travers ces récits et ces admonestations conférant aux femmes de tout âge la capacité et le devoir d'intervenir dans leur milieu, l'Église s'attribue une faculté émancipatrice, celle de libérer le sexe féminin de «l'esclavage» en lui assignant une mission à la mesure de ses aptitudes et de ses qualités «naturelles ${ }^{39}$ ». Cette «émancipation» reste cependant fort limitée. En se fondant sur le concept de complémentarité des sexes, les penseurs catholiques circonscrivent la sphère d'activité de chacun:

La mission des femmes est moins, en général, d'expliquer la vérité que de la faire sentir. Marie ne révéla pas le Verbe divin, mais elle l'enfanta par la vertu de l'Esprit Saint. Ici on retrouve encore un type du ministère de la femme et du ministère de l'homme, dans la prédication de la vérité, qui n'est que son Annonciation perpétuée. Pour que la vérité s'empare de nous, il faut d'abord qu'elle soit révélée à notre intelligence: c'est la fonction particulière de l'homme, parce que la faculté rationnelle prédomine en lui [...] Dans la femme prédomine la puissance affective ou le sentiment [...] cette prédominance du sentiment détermine la mission propre des femmes: elle a pour but de faire passer la vérité dans le cœur, de la convertir en amour. Mais le sentiment ne s'enseigne pas, il s'insinue.

[...] Voilà pourquoi la mission inspiratrice, dévolue à la femme, est une mission privée ${ }^{40}$.

On l'aura noté, c'est davantage la fonction du prêtre que celle de tous les hommes qui est définie ici. Qu'elles soient mariées, célibataires ou religieuses, mères de famille, aides domestiques ou institutrices, les femmes peuvent, d'une façon ou d'une autre, appliquer à leur vie les exhortations cléricales. Pour les hommes, il en va autrement. À l'exception des prêtres, qui peut se sentir concerné par ce devoir d'expliquer la vérité, celle-ci étant, dans le contexte particulier du texte, le message évangélique? À bien des égards, ce discours insiste beaucoup plus sur les responsabilités féminines que sur celles des hommes. Tandis qu'implicitement, on affranchit ces derniers d'une partie de leur rôle en matière d'éducation religieuse et morale, on tend à culpabiliser les femmes n'ayant pas réussi à faire de leurs

39. Ce thème est par exemple développé dans A. Mailloux, op. cit., 321. Il fournit un sujet de dissertation aux élèves de couvent de Saint-Hyacinthe lors des examens publics qui terminent l'année scolaire 1854-1855. Archives du Séminaire de Saint-Hyacinthe, ASE 6: Administration 11.2.21, coupures de presse. Les ministres protestants de la Nouvelle-Angleterre tiennent des propos semblables. Voir Nancy F. Cott, The Bonds of Womanhood. Women's Sphere in New England, 1780-1835 (New Haven, Yale University Press, 1977), 130.

40. Mélanges religieux, 3,14 (8 avril 1842): 219. 
proches de bons chrétiens. Toute limitée qu'elle soit, la tâche confiée aux femmes est, en définitive, exigeante. Elle les contraint à adopter, très jeunes, nombre d'attitudes et de comportements rigides, correspondant aux «vertus de leur sexe». Comment les femmes ont-elles compris cet enseignement? Comment l'ont-elles appliqué à leur vie personnelle? Consultons, à ce propos, leurs lettres et leurs journaux intimes.

\section{LA PORTÉE DU DISCOURS CLÉRICAL}

Les écrits des femmes laïques du $\mathrm{XIX}^{\mathrm{e}}$ siècle contiennent maintes réflexions témoignant de l'importance de la religion dans leur vie et de l'efficacité des enseignements cléricaux. Toutes ne posent cependant pas le même regard sur leur propre expérience spirituelle. Derrière des propos à première vue répétitifs et stéréotypés sur les cérémonies religieuses et sur les pratiques de piété perce une grande diversité de commentaires reflétant la personnalité de chacune, son milieu social et familial, ainsi que son éducation.

\section{Réflexions de retraite}

Plusieurs observations et remarques concernent les retraites spirituelles. Dans leurs journaux personnels et dans leurs lettres, les femmes révèlent leurs dispositions et les attentes qu'elles nourrissent au moment d'entreprendre les exercices. Pour certaines, la retraite semble s'apparenter à un délassement ${ }^{41}$ ou à une succession de sermons plus magnifiques et instructifs les uns que les autres ${ }^{42}$. Ces femmes inscrivent soigneusement les thèmes des sermons dans leur journal intime qui devient un outil de perfectionnement spirituel. À 15 ans, Marie-Louise Globensky note tous les détails d'une instruction sur sainte Agnès prononcée à la retraite du couvent. Le récit, visant à faire comprendre que la «sublime vertu de pureté» est «la plus délicieuse parure», met en scène une jeune fille de bonne famille déshabillée et jetée en prison parce qu'elle a refusé de se marier. Dieu récompense son courage en la dotant d'une longue chevelure couvrant

41. Julie Bruneau à Louis-Joseph Papineau, 1860, dans Rapport de l'archiviste de la province de Québec (dorénavant RAPQ), 39 (1958-1959): 181.

42. Ainsi en est-il des nombreux commentaires laissés par Marie-Louise GlobenskyLacoste et par Angélique Hay-DesRivières dans leurs journaux intimes conservés respectivement aux ANQM et à la bibliothèque de l'Université McGill. La même remarque s'applique au journal attribué à madame Cyrille Tessier (Appoline Mackenzie) et conservé aux Archives nationales du Québec à Québec (désormais ANQQ), P0245-2. Ce journal compte dix volumes couvrant les années 1870-1880. Je doute, pour ma part, qu'il ait été écrit par cette femme. S'il faut se fier à la signature apparaissant sur la page de garde du cahier de 1878, il serait l'œuvre d'Anne M. Morrogh. 
sa nudité. Sa vertu impressionne son prétendant qui, finalement, se convertit. De cette histoire, Marie-Louise retient surtout que «Dieu aime et protège les âmes pures ${ }^{43}$ ».

À la différence de la jeune Globensky, d'autres retraitantes montrent un enthousiasme mitigé à l'égard des retraites spirituelles. Heureuse de songer aux heures de silence que lui laissera cette période de recueillement, Henriette Dessaulles n'en critique pas moins les prédicateurs qui, d'une année à l'autre, offrent «toujours le même ressassage ${ }^{44} »$. Pour cette jeune fille de la bourgeoisie libérale de SaintHyacinthe, la plupart des prêtres font montre de bien piètres talents oratoires et ne réussissent guère à toucher l'âme. Influencée peut-être par le milieu qui l'a vue grandir, elle aspire à un discours religieux dénué de menaces et de condamnations terrifiantes. À ses yeux, le formalisme des exercices ne porte pas à la ferveur. Aussi doute-t-elle que ses compagnes soient aussi recueillies que le laissent croire leurs airs méditatifs. «Les autres, mes amies, prétendent qu'elles se convertissent. Le croient-elles, est-ce vrai? Se convertir, c'est un mot qu'elles disent! ce ne sont pas des criminelles pas plus que moi $^{45}$.» Entre les périodes consacrées à la méditation, qui lui laissent le temps de penser à ses proches, notamment à son père, à sa belle-mère et à Maurice, son futur époux, elle apprécie le chant des religieuses qui l'aide à prier Dieu. Malgré les critiques qu'elle formule, elle termine sa retraite en promettant d'être pieuse, patiente et soumise. Ce faisant, elle agit comme ses contemporaines. Au terme des exercices, les jeunes filles s'engagent en effet à être bonnes, obéissantes et studieuses, alors que leurs aînées aspirent aux vertus de charité, de dévouement, de patience et de courage auxquelles les prêtres les ont exhortées. Certaines se disent déterminées à ne plus danser «de danses vives» ou à ne plus lire de romans. Toutes résolvent d'accomplir diverses pratiques de piété. Joséphine Marchand décide ainsi de «faire tous les jours un quart d'heure de méditation», de se confesser et de communier tous les quinze jours, afin de parvenir à la «fidélité, la persévérance dans le service du bon Dieu» et d'afficher «une foi inébranlable ${ }^{46}$ ».

43. ANQM, P76/6, Journal de Lady Lacoste (Marie-Louise Globensky), 19 octobre 1864.

44. H. Dessaulles, op. cit., 7 octobre 1879,540 . Voir aussi les pages 200 à 209 où il est question d'une autre retraite. Henriette Dessaulles est née le 6 février 1860 du mariage de Georges-Casimir Dessaulles et d'Émilie Mondelet. Elle est l'auteure de plusieurs chroniques publiées sous le pseudonyme de Fadette.

45. Ibid., 3 octobre 1875, 204.

46. Archives nationales du Canada (dorénavant ANC), MG 27 III B3, volume 8A, Journal de Joséphine Marchand-Dandurand, souvenir de retraite, mars 1884, 13-14. Joséphine est née le 5 décembre 1861 à Saint-Jean-sur-Richelieu. Fille du libéral Félix-Gabriel Marchand, elle épousa Raoul Dandurand le 12 janvier 1886. Elle est la fondatrice de la première revue féminine au Québec: Au coin du feu. 
Ces résolutions d'une jeune femme de 23 ans sont prises en mars 1884 , à la fin d'une retraite de cinq jours au couvent des Dames du Sacré Cœur de Jésus, au Sault-aux-Récollets. Une religieuse a personnellement invitée Joséphine à cette récollection qui, a priori, ne l'inspire guère: «Elle me réinvite pour aller faire une retraite. Il n'y a plus moyen de résister. Il faut me rendre. J'en suis malade. Dans la disposition actuelle de mon esprit et de mon âme tournés de n'importe quel côté excepté de la religion, c'est une tâche affreuse ${ }^{47}$.» Au début des exercices qui doivent l'aider à déterminer sa vocation, Joséphine avoue sa difficulté à sortir de son «engourdissement spirituel» et à «entrer tout à fait en Dieu»:

Le bon Dieu ne me donne pas pendant ma retraite des consolations sensibles, affirme-t-elle le troisième jour. J'ai toujours l'âme sourde-muette et engourdie à l'endroit des choses spirituelles. Le fait est que je ne sais pas où est allé mon cœur. J'entends bien ses pulsations mais je n'ai pas connaissance de ses sentiments. Il dort ou il est mort pour tout. Serais-je trop peu généreuse pour le bon Dieu? ${ }^{48}$

Parfois, la retraitante se laisse aller à la rêverie et à la badinerie: «Il y avait dans ma méditation très sérieuse de ce matin, un mot qui m'a fait rire: 'Quomodo cecidisti Lucifer?', ce qui veut dire 'Comment es-tu tombé Lucifer?'. J'ajoutais involontairement:'T'es-tu fait mal?' ${ }^{49} . \gg$ Il lui arrive aussi d'adapter les exercices proposés, afin de les rendre plus conformes à ses croyances et d'en tirer de meilleurs fruits. Insensible aux évocations des feux de l'enfer, elle médite sur les supplices de l'âme obligée de revenir sur terre après avoir entrevu les bonheurs célestes, pensée qui correspond mieux que «l'enfer traditionnel» à sa conception de la damnation éternelle. Espérant trouver des réponses à ses interrogations théologiques, elle décide de se confier à son confesseur, mais celui-ci refuse de discuter et qualifie ses doutes de simples «tentations contre la foi». Peu à peu, au cours de la retraite, les méditations sur la mort, sur le salut et sur l'amour de Dieu font leur effet. L'inquiétude la gagne; elle se sent coupable: «Et si je résistais à la grâce», pense-t-elle. À la suite d'une dernière rencontre avec son directeur spirituel, elle en vient même à envisager de prendre le voile: «Après tout, il n'est peut-être pas impossible que je me décide un jour à venir m'enrôler sous la bannière du Sacré-Cœur. Je 1884.

47. ANC, MG 27 III B3, volume 8A, Journal de Joséphine Marchand-Dandurand, 8 mars

48. Ibid, souvenir de retraite, 8 . Voir aussi la page 1.

49. Ibid., 7. 
l'écris sans trembler et c'est un immense progrès. Je serais une élue, une privilégiée ${ }^{50} . »$

Dans les mois qui suivent sa retraite, Joséphine Marchand s'applique à respecter ses promesses. Elle prie et fréquente régulièrement les sacrements. "Qu' on est heureux et tranquille quand on croit», s'exclame-t-elle le 11 mai, précisant, quelques semaines plus tard, qu'elle aspire «à être une bonne catholique pour édifier et convertir ceux qui [lui] sont chers $^{51}{ }^{\prime}$. Son zèle apostolique est alors dirigé vers Raoul Dandurand qu'elle fréquente assidûment depuis quelque temps. $\mathrm{Au}$ cours de sa retraite, elle avait avoué à son directeur spirituel ses relations avec ce jeune homme, confidence qui l'avait bientôt forcée à défendre la foi et les mérites religieux de celui qu'elle songeait à épouser. Même s'il assistait aux offices et accomplissait son devoir pascal, Dandurand, un libéral proche de la famille Doutre, était considéré comme un impie. À force d'arguments, son confesseur avait fait promettre à Joséphine «de ne pas épouser M. Dandurand sans être moralement convaincue qu'il sera un bon et un vrai catholique ${ }^{52} »$. Sa foi et celle de leurs futurs enfants en dépendaient. La retraitante s'était promise de faire son possible pour ranimer la ferveur religieuse de son prétendant, consciente que toutes ses tentatives allaient peut-être échouer. C'est dans cet état de découragement, pressée par les conseils de son directeur de conscience, qu'elle en vint à considérer la vocation religieuse.

Selon son témoignage, ses efforts auprès de Raoul Dandurand s'avérèrent fructueux. Au mois d'août, les fiancés convinrent de s'épouser en janvier 1886. Le jeune homme était métamorphosé:

Il a mis tant de bonne volonté à obéir à mon vœu de le voir un bon catholique qu'il en est arrivé à ce point de prier maintenant, avec ferveur la Providence [...]

Entouré de ses amis, tous intelligents mais libres penseurs, qui s'étonnent de ce qu'ils appellent son mysticisme, qui le raillent et lui disent qu'il cède aux femmes, malgré tout, il croit, il veut croire et prier parce que je le souhaite ardemment ${ }^{53}$.

Le zèle religieux du «converti» fut parfois chancelant, mais elle l'en excusa. Quand, un dimanche matin, il resta au lit et rata la messe dominicale, elle se reprocha d'avoir elle-même manqué de piété: «Il

50. Ibid., 13.

51. Ibid., 11 mai 1884 et $1^{\text {er }}$ juin 1884 .

52. Ibid., souvenir de retraite, 11.

53. Ibid., 30 août 1885 . 
fait tout ce que je veux quand je sais le vouloir avec fermeté ${ }^{54} . »$ Joséphine Marchand, plus tard connue pour ses publications et son militantisme féministes, considérait alors avoir failli à sa mission, celle d'édifier son fiancé.

\section{Conseils et prières d'épouses et de mères}

Comme Joséphine Marchand, plusieurs femmes furent très préoccupées par la piété de leurs proches. Les lettres de Julie BruneauPapineau renferment maintes exhortations adressées à ses fils et à son mari pour qu'ils soient fidèles à accomplir leurs devoirs de catholiques. Julie s'inquiétait de leurs négligences, allant même jusqu'à en porter la responsabilité. Dans un mot à son fils Lactance, elle affirmait en 1836: «Je regrette beaucoup de ne pas t'avoir écrit plus souvent [...] je m'en fais des reproches; c'était mon devoir de te rappeler de tems en tems [sic] tes devoirs tu ne te serais peut-être pas laissé aller à la négligence et à l'indifférence ${ }^{55}$.»

Vers la même époque, la veuve de Lanaudière-Baby recommandait à son garçon d'être pieux, bon et honnête ${ }^{56}$. Une autre, sans doute influencée par la prédication et par les associations pieuses mises en place à compter de 1840 , commença à prôner la tempérance. Pour elle, «religion et sobriété» étaient «des choses inséparables ${ }^{57}$ ». Dans leurs lettres et leurs journaux, les femmes aspiraient à faire de leurs proches de bons catholiques qui appliqueraient avec zèle les enseignements du clergé. L'une d'elles, Angélique Hay-DesRivières, posait un regard inquiet sur son fils qui se dirigeait lentement vers l'âge adulte ${ }^{58}$. L'enfant, encore pieux, allait-il conserver ses bonnes dispositions? Continuerait-il de prier avec ferveur la Vierge et les saints? Ferait-il toujours des retraites? Allait-il garder l'habitude de communier plusieurs fois par année en se recueillant pieusement? Cette mère se réjouissait chaque fois que son garçon accomplissait un acte de piété et formulait des prières pour qu'il persévère dans sa bonne conduite. Les mêmes gestes accomplis par sa fille ne faisaient pas l'objet d'autant d'attention. Espérait-elle secrètement que son fils embrasse la prêtrise? Redoutait-elle plutôt qu'il adopte un comportement semblable à celui de son père et de son oncle et qu'il limite sa

54. Ibid., 15 octobre 1885.

55. Julie Bruneau à Lactance, 7 décembre 1836, $R A P Q, 38$ (1957-1958): 80.

56. Archives de l'Université de Montréal (dorénavant AUM), Collection Baby, U/6724 et U/6734, lettres du $1^{\text {er }}$ mars 1837 et du 31 octobre 1839 .

57. AUM, Collection Baby, U/6909, Marguerite de Lanaudière à George Baby, 13 janvier 1856.

58. McGill, Mme Henri DesRivières (Angélique Hay), Personal diary. 
pratique aux rites obligatoires? La seconde hypothèse semble plus plausible. Il était pour elle normal qu'une jeune fille soit pieuse et qu'elle satisfasse à l'idéal catholique. Pour un homme, les choses pouvaient être différentes. Et elles le furent effectivement. Les mentions concernant la pratique religieuse de Willy se raréfièrent quand celui-ci atteignit la vingtaine. Madame Hay-DesRivières communiait désormais seule ou avec sa fille Caroline.

Souvent, les prières que les femmes adressaient à Dieu, à la Vierge ou aux saints visaient à obtenir que tous les membres de la famille persévèrent dans leurs bonnes dispositions ou qu'ils se «convertissent». Le journal que Marie-Louise Globensky-Lacoste tint pendant de nombreuses années contient de fréquentes allusions à ce sujet. Chaque nouvelle étape de la vie s'accompagnait d'une prière d'intention. L'admission des enfants au couvent ou au collège, la fin de leurs études, leur anniversaire, leur première communion, leur mariage, la naissance des petits-enfants fournissaient à la diariste l'occasion d'inscrire diverses invocations. Dans ses écrits, la vie paraît semée d'embûches, se présentant comme une route qu'il faut parcourir avec la divinité afin d'obtenir le salut éternel. Quand, par exemple, l'un de ses fils quitte définitivement le pensionnat des Jésuites, en février 1894, elle énonce le souhait suivant: «Que Dieu le protège maintenant et lui fasse éviter les écueils qui seront sur son chemin ${ }^{59} . »$ Une prière semblable est faite le jour de sa réception au barreau: «Que Dieu maintenant le guide dans sa nouvelle carrière, qu'il soit prêt à marcher dans le chemin du devoir ${ }^{60}$.» Cette femme se sentait responsable de l'âme de chacun de ses enfants. Le jour de son trente-cinquième anniversaire de mariage, elle consigne les pensées qui lui avaient traversé l'esprit en entendant la messe matinale:

Je me sentais pleine de reconnaissance et mon cœur déborda en actions de grâce pour mon Dieu qui toujours me protégea et me donna presque la main, pour m'aider à traverser les sentiers épineux, car sur le chemin de roses quel qu'il soit ne faut-il pas rencontrer quelques épines? Puis cette Vierge bénie qui fut toujours ma mère, je lui fis promettre d'être aussi celle de mes chers enfants que je lui offre comme un bouquet précieux à sa garde $^{61}$.

Dans ce journal, de très nombreux passages vantent les vertus protectrices de la Vierge Marie. Elle s'y révèle comme un modèle et

59. ANQM, P76/6, Journal de Lady Lacoste (Marie-Louise Globensky), 28 février 1894.

60. Ibid., 9 juillet 1897

61. Ibid., 8 mai 1901. 
un soutien pour les femmes. Figure maternelle par excellence, elle inspire confiance. Pour cette raison, Lady Marie-Louise cultive la dévotion mariale chez ses enfants. À sa naissance, la petite Berthe est consacrée à la Vierge, ce qui lui vaut d'être uniquement vêtue de bleu jusqu'à l'âge de huit ans ${ }^{62}$. Tous, filles et garçons, portent le scapulaire de Notre Dame du Mont Carmel, comme le font alors nombre de fidèles de tout âge et de toute condition sociale. Elle les enrôle dans la congrégation des Enfants de Marie et les encourage à garder toujours sur eux la médaille de cette association. C'est d'ailleurs à cette médaille qu'elle attribue le sauvetage de sa fille Yvonne, rescapée «par miracle» des eaux du fleuve ${ }^{63}$.

Fréquemment, Marie-Louise Globensky-Lacoste recourt aux allégories utilisées par les clercs pour prier et pour exprimer ses joies, ses peines et ses espérances. Comme ses contemporaines qui collectionnent les images pieuses ou les pensées édifiantes ${ }^{64}$, elle affectionne le vocabulaire stéréotypé des sermons et des livres de dévotion. Des contrariétés en apparence mineures lui donnent prétexte à évoquer les souffrances de la maternité. En songeant à la villégiature estivale et à la séparation temporaire de la famille qui allait en résulter, elle s'exclame: «Hélas! que de ronces nous rencontrons à mesure que nous avançons, nous serions parfois désespérés, si la foi ne nous soutenait, à la pensée que Dieu saura un jour les transformer en roses pour en tresser notre couronne ${ }^{65}$.» La conviction que la vie est une vallée de larmes, surtout pour les épouses et pour les mères, semble avoir été profondément intériorisée par cette femme de la bourgeoisie montréalaise. Toutes n'affichaient cependant pas la même propension à dramatiser la moindre difficulté. Joséphine Marchand affichait plutôt de l'optimisme et dénonçait cette tendance à concevoir le mariage et la vie en général comme une succession d'épreuves ${ }^{66}$. Chez d'autres encore, l'attitude face à la vie était essentiellement faite de résignation et d'acceptation silencieuse des difficultés. En somme, les femmes reformulaient selon leur tempérament le discours doloriste et sentimental des prêtres.

62. Ibid., 16 mars 1897.

63. Ibid., 17 juillet 1901. Henriette Dessaulles portait aussi une médaille de la Vierge. Lors de ses vacances à Old Orchard, elle explique à un protestant pourquoi elle croit si fermement que la Madone protège et «console tous ceux qui souffrent». H. Dessaulles, op. cit., 6 août 1876, 277.

64. AUL, P 224, Journal d'Anna de Gonzague, 26 décembre 1892; ANQQ, P0245-2, Journal de Mme Cyrille Tessier, coupures de presse insérées dans le cahier de 1880 .

65. ANQM, P76/6, Journal de Lady Lacoste (Marie-Louise Globensky), 30 avril 1901.

66. ANC, MG 27 III B3, Journal de Joséphine Marchand-Dandurand, 14 octobre 1883 et 4 novembre 1897. 
Une différence importante apparaît par ailleurs quand on compare les écrits de la fin du XVIII et du début du XIX ${ }^{\mathrm{e}}$ siècle avec les lettres et les journaux postérieurs. La correspondance des familles de Lanaudière et de Lavaltrie, celle de Julie Bruneau-Papineau et de plusieurs contemporaines font souvent référence à «la Providence qui décide» et à «cette main invisible qui nous frappe ${ }^{67}$ ». Elle montre que l'image du Dieu justicier, dont les décisions sont sans appel, est à cette époque profondément imprégnée dans les mentalités. Par comparaison, les témoignages subséquents laissent une large place à la Vierge, au Sacré Cœur, à saint Joseph et à sainte Anne et insistent sur la miséricorde et sur la bonté divines. Tout au long du siècle, l'idée de résignation et de soumission aux puissances célestes resta vivace, mais la confiance accordée aux saints protecteurs modifia quelque peu le ton du discours religieux. Leur possible médiation auprès de Dieu permettait d'espérer. Ils apparaissaient comme de précieux alliés, capables de plaider en faveur des fidèles, de les soutenir et de les aider à devenir meilleurs.

Cet enseignement plus rassurant ne fit cependant pas disparaître la peur de Dieu et le sentiment de culpabilité, comme l'illustrent les cahiers d'Henriette Dessaulles. Nous l'avons vu, cette jeune femme exprimait des idées toutes personnelles sur la religion. Parfois, elle émettait des réserves sur l'enseignement des prêtres. Loin d'être toujours marquées par la quiétude, les confidences qu'elle coucha dans son journal intime laissent au contraire deviner le remords. Les remises en question et l'ennui que suscitaient chez elle certaines cérémonies religieuses lui donnaient parfois l'impression de n'être pas assez pieuse et de ne pas mériter pleinement la sollicitude du Dieu amour qu'exaltait la piété ultramontaine. «Mes prières sont laides!», écrivait-elle en 1875. «Je les dis sans y penser, sans l'aimer le grand bon Dieu qui ne m'écrase pas comme je le ferais si j'étais Lui!68》 Henriette entretenait de la divinité une image ambivalente, oscillant entre la bonté et la sévérité, et que révèlent surtout ses réflexions sur la souffrance et sur la mort ${ }^{69}$. Par ailleurs, son amour naissant pour Maurice lui inspirait de la culpabilité: elle se demandait pourquoi elle n'éprouvait par le même sentiment pour Dieu:

Pour le bon Dieu, je suis froide et sèche. Quand je souffre, je lui crie égoïstement d'avoir pitié de moi, mais s'll m'exauce et me comble je me force à lui dire merci. Et vrai, je ne puis me voir si laide et ingrate sans être bouleversée. Je voudrais l'aimer le

67. AUM, Collection Baby; RAPQ, 1957-1958 et 1958-1959, 38-39: 55-184.

68. H. Dessaulles, op. cit., 12 juillet $1875,175$.

69. Ibid., 7 mars 1875,$143 ; 30$ mars $1875,150-151 ; 15$ octobre 1875, 212; 23 octobre $1875,215$. 
bon Dieu mais ce désir dure un moment, un éclair! Habituellement j'y pense à peine! Je me laisse absorber par mon amour. C'est ma pensée constante, mon but unique, ma seule préoccupation. Plus je vais, moins je m'appartiens. Rien ne me touche de ce qui n'est pas Maurice, et mes seules bonnes prières sont celles que je fais pour lui, pour nous ensemble ${ }^{70}$.

En vieillissant Henriette se sentit devenir responsable de la conduite de son futur mari. À l'approche de son mariage, elle pria sa mère défunte et la Vierge de l'aider dans la tâche qui allait bientôt lui incomber, celle de veiller sur l'âme de Maurice ${ }^{71}$. Malgré ses propres réticences à l'égard du sacrement de pénitence, elle l'incita à se confesser pour, qu'il se conforme, en tous points, au modèle exemplaire du bon chrétien.

\section{La confession}

$\mathrm{Au} \mathrm{XIX}^{\mathrm{e}}$ siècle, la confession était un geste grave et sérieux à propos duquel les femmes s'exprimaient souvent en termes voilés. Marqué du sceau de la confidentialité, elle demeurait un acte dont on parlait peu, si ce n'est pour se réjouir d'avoir obtenu l'absolution, préalable à la communion. Parmi celles qui s'attardèrent un peu plus longuement sur leurs confessions, Henriette Dessaulles déplorait «la manie de questionner» de l'abbé Jean-Joël Prince. «Je veux accuser mes péchés, c'est tout!», s'exclama-t-elle, un jour, au sortir du confessionnal. «Il n'a pas le droit d'essayer de me tourner comme une poche que l'on vide...72 » Aspirant à un échange authentique, elle rêvait d'un confesseur doté de «beaucoup de divination, d'indulgence et de fermeté», capable de «s'élever assez pour [1']entraîner à sa suite ${ }^{73}$ ». Sans remettre en cause l'obligation de confesser ses péchés, elle aurait aimé pouvoir le faire en s'adressant directement à Dieu.

D'autres témoignages démontrent que, lorsqu'il leur était possible de le faire, les femmes prenaient grand soin de bien choisir leur confesseur. Elles souhaitaient rencontrer chez lui un certain nombre de qualités. Moins exigeantes ou peut-être plus chanceuses qu'Henriette Dessaulles, plusieurs trouvèrent celui qui répondait à leurs attentes. $\mathrm{Au}$ retour des vacances estivales, Marie-Louise Globensky-Lacoste revoyait son directeur de conscience avec un contentement toujours

70. Ibid., 13 août 1879,502 .

71. Ibid., 18 mai 1881, 614. Voir aussi $1^{\text {er }}$ août 1879, 490 et 27 septembre 1879, 535 .

72. Ibid., 21 septembre 1876, 294. Sur la confession, lire Serge Gagnon, Plaisir d'amour et crainte de Dieu. Sexualité et confession au Bas-Canada (Québec, Presses de l'Université Laval, 1990), 202 p.

73. Ibid., 11 mai $1878,443$. 
renouvelé. Elle ne se confiait qu'avec réticence à un autre prêtre. Parfois, le confesseur devenait un véritable ami. Au tournant du XIX ${ }^{\mathrm{e}}$ siècle, mademoiselle de Lavaltrie entretint pendant plusieurs années une correspondance assidue avec l'abbé René-Pierre Joyer, son ancien directeur spirituel, qui fut muté à une paroisse trop éloignée de celle de sa pénitente pour continuer son ministère auprès d'elle ${ }^{74}$. À celle qu'il appelait «sa tendre et obligeante sœur et bonne amie», ce prêtre prodiguait des conseils de natures diverses. Il lui faisait part de ses réflexions spirituelles, lui conseillait des lectures, disait des messes à son intention et tentait d'apaiser ses peines et ses misères domestiques. De temps à autre, il la réprimandait parce qu'elle tardait à se confesser, parce qu'elle accordait trop d'importance à sa santé ou simplement parce qu'elle se montrait trop généreuse pour sa jeune servante. «Les blessures d'un ami valent mieux que les baisers d'un flatteur», lui disait-il à ces occasions. En reconnaissance de ses avis et de ses attentions, mademoiselle de Lavaltrie lui envoyait des vivres ou de l'argent pour ses propres besoins ou pour les pauvres de sa paroisse. À au moins deux reprises, elle dépêcha une de ses domestiques auprès de son ami malade. Pour cette vieille célibataire, le confesseur était devenu, au fil du temps, un confident disposant d'un réel ascendant sur sa pénitente.

Cette importance du confesseur, Joséphine Marchand la souligna également dans son journal. Informée du décès du curé Aubry, son premier directeur spirituel, elle lui rendit un hommage teinté de nostalgie:

La première fois que, le cœur angoissé, le souffle coupé par une suppliciante timidité, j'entrai dans la boîte aux péchés dont la grille était trop haute même en me tenant debout, c'est M. Aubry qui m'appela, me fit entrer dans son confessionnal pour mieux m'entendre. Agenouillée devant lui, les mains jointes sur ses genoux, encouragée par sa voix bienveillante mais sans oser lever les yeux, seulement sur le bord de son surplis, et défaillante de confusion, je dus me résigner à cette posture pendant, je pense bien, deux ans. Il m'en coûtait moins quoique toujours beaucoup d'aller à confesse, quand je pus comme les autres, cacher ma «honte et mon remords» derrière une grille. Ce fut encore lui qui me confessa la veille de mon mariage et lui qui me maria. Je ne sais s'il s'est jamais rendu compte qu'il avait été, depuis le commencement, le confident de ma vie ${ }^{75}$.

74. Les lettres de l'abbé Joyer sont conservées aux AUM, collection Baby. Il n'a pas été possible de retrouver celles de mademoiselle de Lavaltrie.

75. On commence alors à se confesser vers l'âge de 7 ans. La première communion se fait quant à elle vers 11-12 ans. ANC, MG 27 III B3, volume 8A, Journal de Joséphine Marchand-Dandurand, 10 janvier 1898, 102. 
Si les femmes attachaient autant d'importance à leur confesseur, c'est que celui-ci leur apparaissait comme le dépositaire de leurs aveux. La confession était une démarche difficile, mais semblait faire l'objet de bien peu de remises en question. Ce rite imposé par l'Église devait précéder la communion que les prêtres du $\mathrm{XIX}^{\mathrm{e}}$ siècle encouragèrent avec une insistance croissante. Les nombreux passages faisant référence à ce sacrement dans les écrits des femmes laissent deviner, ici aussi, un fort degré d'intériorisation des enseignements de l'Église.

\section{La communion}

C'est surtout dans les journaux intimes et dans les lettres de la seconde moitié du siècle que la communion est évoquée. Les femmes font écho aux sermons des curés et célèbrent «le bonheur de communier». L'eucharistie s'y révèle le sacrement par excellence qui commémore les grands événements de la vie, répare les torts faits à Dieu, fortifie et guérit l'âme. Dans chacun des six journaux intimes consultés, les communions sont soigneusement notées. On reçoit ce sacrement aux grandes fêtes chrétiennes, à son anniversaire de naissance, à celui de son mari ou de son fiancé, à ceux des enfants et des parents décédés.

Pour les femmes, communier est un événement majeur. En conformité avec le discours ultramontain, elles conçoivent la communion comme une rencontre avec le «bon Dieu» ou le «doux Jésus», qu'il faut s'efforcer de bien préparer. Chez certaines, elle apparaît même comme une expérience extatique les transportant dans un état de ravissement ou de douce sérénité. Malgré l'importance attachée à ce sacrement, les témoins font, en général, peu état de leurs scrupules. En décembre 1874, Henriette Dessaulles regrette d'avoir éprouvé de la rancœur et de la jalousie le jour de sa communion ${ }^{76}$, mais pareilles révélations sont plutôt rares. Dans l'ensemble, les femmes ne s'interrogent pas sur leurs dispositions. Si elles le font, elles n'en laissent, en tout cas, aucune trace écrite. Le fait d'avoir reçu au préalable l'absolution de leurs péchés leur apparaît peut-être comme une excellente garantie de leurs aptitudes morales à communier. En fait, un sentiment de fierté est plutôt associé à la réception du sacrement. Contrairement à la confession, la communion est un acte public que l'on aime accomplir avec un être cher. Ainsi, quelque temps avant son mariage, Henriette Dessaulles écrit: «Maurice a gagné une cause et il est content. Nous ferons nos pâques ensemble $e^{77}$.» Marie-Louise

76. H. Dessaulles, op. cit., 8 décembre 1874, 126-127.

77. Ibid., 18 mars 1881, 609. 
Globensky-Lacoste laisse plusieurs témoignages semblables. Elle note en 1899: «Ce matin $1^{\text {er }}$ vendredi du mois, j'ai eu le bonheur de communier avec mes cinq filles»; "Aujourd'hui c'est la publication des bancs de ma chère Justine, par conséquent je vais avec elle à la basse messe et nous y avons le bonheur de communier ${ }^{78}$.» Dans son journal, la jeune institutrice Anna de Gonzague veille pour sa part à inscrire le nom des membres de sa famille qui reçoivent l'eucharistie en même temps qu'elle ${ }^{79}$.

Si les femmes ressentent une telle fierté, c'est sans doute que, pour elles, se présenter à la «sainte table» avec l'époux ou les enfants, c'est afficher devant la communauté paroissiale la force des liens familiaux, tant exaltés par la piété ultramontaine. En même temps, ce geste permet de proclamer ouvertement l'adhésion du groupe familial aux valeurs religieuses prônées par le clergé. Il démontre en quelque sorte que la famille, placée sous la gouverne spirituelle de la femme, répond aux attentes de l'Église et s'efforce de plaire à Dieu. Au moment même où les prêtres mesurent de plus en plus la valeur religieuse et morale des fidèles à l'aulne de leurs communions ${ }^{80}$, ce sacrement accompli publiquement, en famille, témoigne que l'épouse, la mère, la fille sont parvenues à remplir leur mission.

\section{CONCLUSION}

Au terme de ce survol visant à mieux connaître les contenus spirituels et à donner la parole aux femmes à qui s'adressaient l'enseignement des prêtres, on peut dégager plusieurs observations et proposer des pistes de recherche. Comme nous l'avons vu, le discours clérical accorda, au XIX ${ }^{\mathrm{e}}$ siècle, une place croissante aux images empruntées au quotidien des femmes. Fréquemment, il faisait référence au mariage, à la maternité et à l'univers domestique. À travers ces évocations propres à donner aux auditrices et aux lectrices l'impression d'être comprises et appréciées par l'Église se dessinait un idéal féminin. La femme modèle se signalait par sa dévotion et par ses mœurs irréprochables. Elle était à la fois faible et forte, puisque sa fragilité et sa sensibilité «naturelles» étaient porteuses de puissance et lui conféraient un ascendant sur les autres. Il lui revenait de mettre à profit ces qualités valorisées par la piété ultramontaine pour détourner ses proches du «vice» et des «mauvaises doctrines» et pour les inciter à

78. ANQM, P76/6, Journal de Lady Lacoste (Marie-Louise Globensky), 2 juin et 22 octobre 1899.

79. AUL, P 224, Journal d'Anna de Gonzague. À titre d'exemple, voir le 11 septembre et le 13 novembre 1892 .

80. C. Hudon, Encadrement clérical..., op. cit., en particulier 425 à 449. 
se conformer aux prescriptions ecclésiales. Alors que la sphère politique offrait aux hommes une nouvelle tribune, de nouveaux intérêts et une nouvelle sociabilité susceptibles de les éloigner de la religion, une véritable offensive pastorale fut lancée pour alimenter la piété des femmes, afin qu'elles assurent la transmission des valeurs religieuses et contribuent à maintenir l'influence de l'Église. À la même époque, nombre de penseurs laïcs reconnaissaient aussi aux femmes une tâche particulière. Ils encensaient la vie familiale et cherchaient à confiner l'activité féminine à l'espace domestique où, disaient-ils, elles étaient aptes à faire le bien.

Ce discours célébrant l'importance et l'influence des femmes avait sa contrepartie. Malgré une habile rhétorique évoquant le caractère émancipateur du christianisme, les propos cléricaux soulignaient surtout la lourde responsabilité des jeunes filles, des mères et des épouses. Les femmes étaient considérées comme les gardiennes des valeurs et de l'ordre établi. Si la tiédeur religieuse de certains hommes était déplorée, celle des femmes était dénoncée plus vigoureusement par le clergé, car elle apparaissait comme une incongruité attestant du piètre état moral et religieux d'une société. Les déclarations de plusieurs prêtres illustrent les attentes différentes qui pesaient sur les deux sexes, ainsi que les comportements dissymétriques que ces attentes ont engendrés et qu'ont déjà mis en évidence Brigitte Caulier et Marie-Aimée Cliche. Afin d'illustrer l'immoralité et l'impiété exceptionnelles de ses paroissiens, un curé soulignait que «même des femmes» négligeaient le confessionnal et les offices ${ }^{81}$. Au début du $\mathrm{XX}^{\mathrm{e}}$ siècle, des confrères mentionnaient qu'une "coutume contraire» et un respect humain touchant particulièrement la partie masculine de la population figuraient au nombre des obstacles à la communion fréquente $^{82}$. À leur avis, beaucoup d'hommes limitaient leur pratique par crainte de «paraître trop dévots». Tout en se pliant aux injonctions de l'Église, ces fidèles évitaient d'afficher une conduite qui leur semblait peut-être trop lourdement chargée de connotations féminines.

81. AESH, XVII, c.7 (Saint-Ange-Gardien), P.-L. Paré à L.-Z. Moreau, 22 avril 1862. Sur le parallèle entre vertus chrétiennes et idéal féminin, lire Nicole Laurin-Frenette et Nadia Fahmy-Eid, «Femmes et Église au Québec: éléments pour une réinterprétation socio-historique», Anita Caron, Femmes et pouvoir dans l'Église (Montréal, VLB, 1991), 55-56. Cette conception n'est pas propre au catholicisme. Elle imprègne aussi fortement le protestantisme américain du $\mathrm{XIX}^{\mathrm{e}}$ siècle. Voir Marta Tomhave Blauvelt, «Women and Revivalism», Rosemary R. Ruether et Rosemary S. Keller, eds., Women and Religion in America, 1: The Nineteenth Century (San Francisco, Harper \& Row, Publishers, 1981), 6.

82. AESH, IV, D.4, renseignements sur la piété et le culte eucharistiques devant servir à la rédaction de travaux destinés au $\mathrm{XXI}^{\mathrm{e}}$ congrès eucharistique international à Montréal, septembre 1910 . 
La correspondance et les journaux personnels reflètent dans une large mesure le discours clérical. Au-delà du style et des procédés énonciatifs ${ }^{83}$ propres à chacun des écrits intimes, au-delà des contextes particuliers et des objectifs spécifiques ayant motivé leur rédaction, on y décèle une caractéristique commune: l'aspiration de leurs auteures à la vertu, leur désir de se conformer à l'idéal proposé. Ces femmes se percevaient comme les premières responsables de la conduite religieuse et morale de leurs proches. Leur spiritualité accordait une large place à la Vierge et aux saints, valorisait les pratiques pieuses, perçues comme les moyens de se concilier les protections divines et d'obtenir le salut éternel. Toutes éprouvaient le sentiment d'avoir manqué à leur devoir quand le fiancé, l'époux ou un enfant passait outre aux prescriptions ecclésiales. Cette culpabilité, cette crainte de ne pas être à la hauteur se manifestaient surtout chez les esprits les plus critiques, comme Henriette Dessaulles et Joséphine Marchand, qui émettaient des réserves à l'égard de certains exercices spirituels, plaisantaient à leurs propos et se montraient impatientes ou exaspérées face à l'attitude de leur confesseur. Faut-il attribuer les particularités de leurs témoignages à l'influence de leur milieu familial? Faut-il conclure qu'ils attestent qu'une petite élite libérale - et seulement elle - épousait une conception de la religion éloignée du discours normatif de l'Église? L'hypothèse est séduisante. Cependant, on pourrait aussi arguer qu'il n'y a que pure coïncidence entre les critiques de ces jeunes filles et leur appartenance sociale. Il est possible, en effet, que leurs remises en question ne soient que le reflet d'une écriture plus libre, qui s'autorise une plus grande franchise. D'autres interrogations surgissent encore: comment les femmes d'origine plus modeste recevaient-elles les exhortations cléricales? Dans quelle mesure et comment l'âge et la situation familiale influençaient-ils le cheminement spirituel? Ces quelques réflexions présentées sous forme de questions pourraient alimenter la recherche sur la religion. C'est dans cette perspective qu'on se prend à rêver de nouvelles sources permettant de saisir plus finement le poids des institutions, de sources qui renseigneraient davantage sur les perceptions et sur les comportements des hommes et des femmes, des différents groupes d'âge et des différents groupes sociaux.

83. Daphni Baudouin a comparé, à ce sujet, quatre journaux utilisés dans cette étude. Voir, «Stratégies énonciatives dans le journal intime féminin du XIX ${ }^{\mathrm{e}}$ siècle», M. Brunet et Serge Gagnon, op. cit., 167-179. 